\title{
ETHNIC BACKGROUND AND RISK PERCEPTION IN CONSTRUCTION WORKERS: DEVELOPMENT AND VALIDATION OF AN EXPLORATORY TOOL
}

\section{FEDERICO RICCI ${ }^{1}$, ALBERTO MODENESE ${ }^{1}$, GIULIA BRAVO ${ }^{1}$, FABRIZIO DE PASQUALE ${ }^{2}$, DAVIDE FERRARI ${ }^{2}$, MASSIMO BELLO ${ }^{1}$, LORENZO CAROZZA ${ }^{1}$, FRANCESCA LONGHI ${ }^{1}$, GIANLUCA FAVERO ${ }^{3}$, SERGIO SODDU ${ }^{4}$, and FABRIZIOMARIA GOBBA ${ }^{1}$}

${ }^{1}$ University of Modena and Reggio Emilia, Modena, Italy

Department of Biomedical, Metabolic and Neural Sciences

${ }^{2}$ Local Health Unit Company, Modena, Italy

Department of Public Health

${ }^{3}$ Observatory for the Prevention, Fontanafredda, Italy

${ }^{4}$ Local Health Unit Company, Bologna, Italy

Department of Public Health

\begin{abstract}
Objectives: Among occupational sectors, construction is still one of the branches with the highest reported numbers of work-related injuries and diseases, which can even lead to death and in many cases induce permanent health consequences. The vast majority of these occupational injuries and diseases are preventable; accordingly, an improvement in preventive strategies, also through a better knowledge of the main factors involved in these events, is one of the most important objectives for better occupational health and safety in the construction sector. Considering the individual factors associated with a higher risk of work-related adverse health effects in workers, an inadequate perception of occupational risks is among the most relevant issues. Risk perception can vary according to different cultural backgrounds, highly influenced by ethnicity, and it affects the relations between workers in the work environment, and the way by with they undergo the specific occupational tasks and manage risky situations frequently occurring on construction sites. Accordingly, the aim of the authors was to develop a new tool for the assessment of risk perception in construction workers with different ethnic backgrounds. Material and Methods: A team of health and safety experts involved in the training of construction workers from various ethnic backgrounds and in different regions of Italy developed and validated a questionnaire-based tool for the evaluation of their risk perception. Furthermore, through a factor analysis, a reference model defining various dimensions of occupational risk perception, relevant for the different ethnicities, was identified. Results: The final tool included 12 items aimed to assess the associations between the ethnic background and occupational risk perception of construction workers. The authors identified 4 relevant dimensions: behavioral control, work conditions, safety climate and personal attitude. Conclusions: The proposed tool should be considered to explore the appropriate ways for the development of effective preventive strategies for construction workers with different ethnic backgrounds in Italy. Int J Occup Med Environ Health. 2020;33(2):163-72
\end{abstract}

Key words:

migrant workers, risk perception, occupational risk, occupational injuries, construction workers, safety culture

Funding: this research was supported by the Regional Environmental Protection Agency of Emilia-Romagna (ARPAE) (project entitled "Percezione e rappresentazione del rischio in edilizia. Studio e analisi di gruppi di lavoratori di diverse nazionalità e culture," project manager: Fabrizio De Pasquale).

Received: May 8, 2019. Accepted: November 5, 2019.

Corresponding author: Alberto Modenese, University of Modena and Reggio Emilia, Department of Biomedical, Metabolic and Neural Sciences, via G. Campi 287, 41125 Modena, Italy (e-mail: alberto.modenese@unimore.it). 


\section{INTRODUCTION}

An adequate risk perception is relevant for the adoption of appropriate protective behaviors, both other- and innerdirected [1]. The authors assume that decision making and risk perception often operate in an intuitive-experiential, fast and automatic way, so people can do mistakes if they do not have access to analytical reason-based tools $[2,3]$. Individuals seem to have limited knowledge of the risks they face in everyday life [4], and so they tend to overestimate certain categories of risks while underestimating others [5].

In 1974, Lalonde [6] noted that people were usually optimistic about the possible consequences of their behaviors, minimizing the probability of undesirable outcomes in dealing with ordinary activities. In these cases, they feel to have a full control of the situation and, accordingly, they believe in a successful conclusion of their actions, with no risks of negative consequences [6]. Considering certain groups of workers, such as construction workers who deal with risky situations on a daily basis [7,8], the ordinariness of their activities may induce a sensation of safety [9]. This may be related to the adoption of faster decision processes, with an insufficient consideration of all the information needed to adequately evaluate risky situations, also taking into account an intrinsic grade of uncertainty [10].

Risk assessment is a consolidated practice performed by technical experts in almost all companies, but it is also a more practical evaluation performed every day directly by workers at their workplaces during their activities. In this latter case, workers usually do not have a clear panorama on all the possible sources of risks, and they cannot use statistical data or other objective information available at a given moment. They make their decisions by evaluating the risk based on information and knowledge deriving from their own experiences, and sometimes their own beliefs [5]. An inadequate knowledge of the factors determining the risk may induce people to trust the opinions of co-workers, often with the same cultural background, considered as experts within their relatively small working groups [11].

Risk perception may vary depending on different sociocultural contexts, which affects the safety risks of migrant workers $[12,13]$. A significant number of migrants work in industrialized countries, but their cultural background is not adequately taken into account when it comes to risk perception. This could be particularly important considering that migrant workers are often engaged in risky tasks with an inadequate level of training, often due to problems in the comprehension of the local language [11].

In Italy, several studies have shown a higher relative risk of occupational injuries for non-Italian workers compared to Italians [14-17], and this finding implicates a relevant issue related to the possibility that trans-culturality may be a factor affecting the occurrence of injuries.

According to these premises, the main scope of this research is the development and validation of an exploratory tool applicable in the Italian construction sector, aimed to evaluate the possible associations between ethnicity and risk perception [13], for a further adoption of more effective preventive interventions, such as specific worker training $[18,19]$.

\section{MATERIAL AND METHODS}

\section{Development of an exploratory tool and pilot administration}

Based on a review of related scientific literature, and on their expertise, a multidisciplinary team composed of experts in occupational medicine, industrial hygiene, psychology, anthropology and sociology conceived and drafted a preliminary version of an exploratory tool [13]. The first step for the team was the identification of 2 quite different Italian regions according to the level of industrialization:

- Emilia Romagna, in particular the districts of Modena and Bologna in the North Italy, which is a highly industrialized area; 
- Sardinia, involving the districts of Cagliari and Oristano: this region is an island in the south-center of Italy, and it is less industrialized.

Then, a detailed analysis of the characteristics of both construction work activities and the working population representing the construction sites of the local districts involved was performed, identifying also the relevant individual and collective preventive measures. This analysis resulted in the first version of a questionnaire, composed of 46 items aimed to evaluate construction workers' risk perception. The workers involved were requested to judge the items of the questionnaire based on the level of agreement or disagreement with the reported sentences, e.g., "My work is dangerous," providing their responses on a 11 pts Likert scale, with $0=$ "absolutely not" and $10=$ "absolutely yes." The authors collected 527 valid questionnaires during the pilot administration (all participants were male).

The pilot administration of the tool was organized at the local vocational schools for construction workers in the $4 \mathrm{mu}-$ nicipal districts involved. In order to avoid any possible misunderstanding in the comprehension of the written Italian language, the administration of the questionnaire was guided by an expert occupational health and safety trainer. Moreover, to avoid possible biases, the compilation of the questionnaire was performed before the training courses so that the workers would not have recent theoretical notions on occupational risks that might influence their responses.

The recipients of the training courses were native and nonnative Italian speaking construction workers from different areas of Italy and the world, attending the training courses in 2009 in one of the included districts. For the consideration of non-native Italian speaking workers, based on a socio-cultural analysis, the authors excluded all the construction workers who were not from Europe or Northern Africa (Algeria, Morocco, Tunisia, Libya, Mauritania and Egypt), in order to warrant an adequate comprehension of the Italian language, as workers coming from these countries usually have an acceptable level of comprehension of Italian. On the contrary, for people from sub-Saharan Africa or from other continents, the level of comprehension of the Italian language exhibits a too much higher inter-individual variability, with some cases of a complete inability to understand the language.

Accordingly, the authors included, in this pilot administration, all the construction workers participating in the training sessions in 2009, who were born in Italy, and also those not born in Italy but with a sufficient ability to understand the Italian language, defined on the basis of their country of origin. No exclusion criteria based on workers' age and sex, or on their years of experience as construction workers in Italy, were conceived.

The questionnaire administration was conducted in accordance with all national regulations and with the principles of the Declaration of Helsinki. Complete information regarding the study project was given to the participants of the training courses, and the subjects were also informed that their participation was voluntary, and that they were allowed to withdraw from the study at any time. The participants' informed consent was collected. Nobody refused to participate or withdrew during the study.

\section{Statistical analysis}

All the data was analyzed using the R i386 software version 3.1.0 for Windows, assuming the significance level of 5\%. A first item analysis was performed to identify non-necessary or highly ambiguous items; the correlation between the mean score assigned to the single item and the mean score of all the items was evaluated using the cut-off correlation value of 0.3 for the identification of the items to be eliminated at the first step. Then, Cronbach's $\alpha$ was calculated to check whether the removed items affected the internal consistency of the questionnaire. The second step was a linear discriminant analysis aimed to identify further items to be eliminated as related to non-homogenous dimensions of judgment within the group of participants. A Wilcoxon test was applied to detect any difference between the first and the third quartile of respondents for each item. 
Table 1. Statistical data of the 527 construction workers involved in the pilot administration of the risk perception questionnaire, according to 4 different areas of origin, in the study on developing and validating a questionnaire that evaluates their risk perception (Italy)

\begin{tabular}{lcc}
\hline & & $\begin{array}{c}\text { Participants } \\
(\mathrm{N}=527)\end{array}$ \\
\cline { 2 - 4 } \multicolumn{1}{c}{ Continent/area of origin } & $\mathrm{n}(\%)$ & $\begin{array}{c}\text { age } \\
\text { [years] } \\
(\mathrm{M}(95 \% \mathrm{CI}))\end{array}$ \\
\hline Europe & & $38(37-39)$ \\
Italy & $390(74)$ & $34(31-37)$ \\
Balkans & $75(14)$ & $33(31-35)$ \\
Northern and Eastern Europe & $47(9)$ & \\
Africa & & $34(28-40)$ \\
North Africa & $15(3)$ & \\
\hline
\end{tabular}

Table 2. Distribution of the 527 construction workers according to their expertise and current job position in the construction sector and their educational level, with respect to 4 different areas of origin, in the study on developing and validating a questionnaire that evaluates their risk perception (Italy)

\begin{tabular}{|c|c|c|c|c|}
\hline \multirow{2}{*}{ Variable } & \multicolumn{4}{|c|}{$\begin{array}{c}\text { Participants' origin } \\
{[\%]}\end{array}$} \\
\hline & Italy & Balkans & $\begin{array}{c}\text { Northern and Eastern } \\
\text { Europe }\end{array}$ & North Africa \\
\hline \multicolumn{5}{|l|}{ Expertise in the construction sector } \\
\hline foreman & 18.59 & 9.52 & 5.80 & 6.25 \\
\hline laborer (generic expertise) & 30.14 & 50.00 & 47.83 & 37.5 \\
\hline $\begin{array}{l}\text { specialized construction worker } \\
\text { (mason, bricklayer, carpenter, etc.) }\end{array}$ & 31.83 & 30.95 & 26.09 & 43.75 \\
\hline other expertise & 19.43 & 9.52 & 20.29 & 12.50 \\
\hline \multicolumn{5}{|l|}{ Job position } \\
\hline currently no job contract & 6.76 & 9.52 & 10.14 & 6.25 \\
\hline permanent employee & 68.73 & 69.05 & 62.32 & 56.25 \\
\hline seasonal worker & 15.77 & 11.90 & 21.74 & 18.75 \\
\hline external collaborator/artisan & 5.07 & 2.38 & 0 & 6.25 \\
\hline other & 3.66 & 7.14 & 5.80 & 12.50 \\
\hline \multicolumn{5}{|l|}{ Education level } \\
\hline no education $(<$ primary school) & 0.28 & 0 & 1.45 & 0 \\
\hline primary school & 60.00 & 30.95 & 24.64 & 43.75 \\
\hline secondary school & 37.75 & 61.90 & 72.46 & 50.00 \\
\hline tertiary school & 1.97 & 7.14 & 1.45 & 6.25 \\
\hline
\end{tabular}


Table 3. The final version of the questionnaire for the evaluation of risk perception in workers with different ethnic background, obtained after a statistical discriminant analysis: the 12 items that showed a significant difference in the Wilcoxon test between the 4 ethnic groups are reported [13]

\begin{tabular}{llc}
\hline $\begin{array}{c}\text { Original } \\
\text { item number }\end{array}$ & \multicolumn{1}{c}{ Item text* } & $\mathrm{p}$ \\
\hline 1 & My job is dangerous & $<0.001$ \\
8 & My specific tasks at the construction site are more dangerous than other jobs in the construction & $<0.001$ \\
9 & sector & $<0.001$ \\
16 & I think it's possible to be seriously injured at work & $<0.001$ \\
18 & My team leader always respects the rules to avoid risks at work & $<0.001$ \\
19 & If we respect the safety requirements, it's possible to avoid occupational injuries & $<0.001$ \\
22 & One can expect to be seriously injured at work & $<0.001$ \\
24 & People working without protective equipment are brave & $<0.001$ \\
30 & My boss wants me to work with absolutely no risks of injuries & $<0.001$ \\
32 & I don't comply with safety rules because my boss tells me that I have to work quickly & $<0.001$ \\
33 & I don't comply with safety rules because I am afraid to lose my job & $<0.001$ \\
\hline
\end{tabular}

* Authors' translation from Italian.

The third step was a factor analysis, with the method of varimax rotation that was performed to highlight a set of non-directly measurable dimensions, within the set of variables derived from the final version of the questionnaire, obtained after the first 2 steps.

At the end, using the 12 acceptable items, the authors identified 4 factors with a threshold factor loading of 0.20 , for the maximization of the mean Cronbach's $\alpha$ values calculated [20], and the items were grouped accordingly.

\section{RESULTS}

Thanks to the collaboration with an anthropology expert, the authors divided data by homogeneous ethnic clusters:

- Balkans - Europe (Albania, Croatia, Kosovo and Serbia),

- Northern and Eastern Europe (Lithuania, Moldova, Poland and Romania),
- North Africa (Algeria, Egypt, Morocco and Tunisia). The mean age, with a $95 \%$ confidence interval, of the different ethnic groups identified in the sample is reported in Table 1, while the characteristics of the subjects according to their expertise and current job position in the construction sector and their educational levels are shown in Table 2.

\section{The first version of the questionnaire and the elimination of unnecessary items}

The first version of the risk perception questionnaire included 46 items; after the pilot administration involving 527 construction workers, the authors performed an item correlation analysis and eliminated 23 unnecessary items, assuming a cut-off value of $<0.3$ (data not shown), in order to simplify the questionnaire and avoid redundancy. Then, a discriminant analysis was 
Table 4. Results of the factor analysis: the loading factors calculated are reported for each item, according to the 4 factors applied in the study on developing and validating a questionnaire that evaluates risk perception of the construction workers (Italy)

\begin{tabular}{lcccc}
\hline \multirow{2}{*}{ Original item number } & \multicolumn{3}{c}{ Factor } \\
\cline { 2 - 5 } & 1 & 2 & 3 & 4 \\
\hline 1 & 0.13 & $\mathbf{0 . 6 5}$ & -0.06 & 0.00 \\
9 & 0.05 & $\mathbf{0 . 7 0}$ & 0.02 & 0.13 \\
9 & 0.12 & $\mathbf{0 . 4 6}$ & -0.04 & 0.11 \\
16 & 0.11 & 0.03 & $\mathbf{0 . 6 1}$ & -0.03 \\
18 & -0.03 & -0.05 & $\mathbf{0 . 5 4}$ & 0.19 \\
19 & 0.01 & 0.14 & 0.11 & $\mathbf{0 . 4 1}$ \\
22 & 0.02 & 0.06 & 0.20 & $\mathbf{0 . 6 1}$ \\
24 & 0.06 & -0.05 & $\mathbf{0 . 5 5}$ & 0.14 \\
30 & $\mathbf{0 . 5 7}$ & 0.10 & 0.11 & -0.02 \\
32 & $\mathbf{0 . 6 3}$ & 0.15 & 0.00 & 0.09 \\
33 & $\mathbf{0 . 6 3}$ & 0.07 & 0.03 & 0.17 \\
34 & 0.20 & 0.03 & -0.01 & $\mathbf{0 . 5 4}$ \\
\hline
\end{tabular}

Bolded are loading factors $>0.02$.

performed, which allowed the authors to identify other 11 additional items that did not show a significant difference between the responses of the 4 groups of subjects, following which only the 12 final items that reported a significant difference, with a $p$ value of $<0.001$, were kept (Table 3).

\section{Factor analysis and identification}

\section{of the dimensions of the exploratory tool}

\section{for the evaluation of workers' risk perception}

With the aim of explaining the correlations between the observed variables, using a smaller number of factors, the authors performed a factor analysis (Table 4 - loading factors) for the final version of the questionnaire (items $\mathrm{N}=12$ ).

Data identified 4 factors that explained human behavior according to the theory of planned behavior [1], integrated with danger perception factors:

- factor 1: perceived behavioral control;

- factor 2: danger perception related to work conditions;
- factor 3: safety climate, producing normative beliefs;

- factor 4: attitude towards safe actions.

Table 5 reports data of the analysis to identify 4 factors defining occupational risk perception in the studied group of construction workers.

\section{DISCUSSION}

This study shows the validation of a useful exploratory tool composed of a 12 items questionnaire enabling the investigation of 4 relevant dimensions involved in the processes of construction workers' risk perception, and possibly useful for the identification of critical dimensions for the recognition of occupational risks according to different cultural backgrounds with respect to the countries of origin. The first dimension identified was named "perceived behavioral control." According to the theory of planned behavior [21], this dimension indicates a measure of the perceived grade of difficulty attributed by a person to the decision of taking a specific action in order to obtain a specific result. In this case, the items included in this di- 
Table 5. Identification of 4 dimensions relevant for the evaluation of risk perception in workers with different ethnic background, based on the results of the factor analysis showing statistical significance of the loading factors for 12-items, then considered the final version of the questionnaire [13]

\begin{tabular}{|c|c|c|}
\hline Factor & Item* & Loadings \\
\hline \multirow{3}{*}{$\begin{array}{l}\text { Perceived behavioral } \\
\text { control }\end{array}$} & 30. I don't comply with safety rules because my boss tells me that I have to work quickly & 0.57 \\
\hline & 32. I don't comply with safety rules because I am afraid to lose my job & 0.63 \\
\hline & 33. I don't comply with safety rules because I am too much tired & 0.63 \\
\hline \multirow[t]{3}{*}{ Danger perception } & 1. My job is dangerous & 0.65 \\
\hline & $\begin{array}{l}\text { 8. My specific tasks at the construction site are more dangerous than other jobs in } \\
\text { the construction sector }\end{array}$ & 0.70 \\
\hline & 9. I think it's possible to be seriously injured at work & 0.46 \\
\hline \multirow[t]{3}{*}{ Safety climate } & 16. My team leader always respects the rules to avoid risks at work & 0.61 \\
\hline & 18. If we respect the safety requirements, it's possible to avoid occupational injuries & 0.54 \\
\hline & 24. My boss wants me to work with absolutely no risks of injuries & 0.55 \\
\hline \multirow{3}{*}{$\begin{array}{l}\text { Attitude towards safe } \\
\text { actions }\end{array}$} & 19. One can expect to be seriously injured at work & 0.41 \\
\hline & 22. People working without protective equipment are brave & 0.61 \\
\hline & 34. I don't comply with safety rules because I am brave & 0.54 \\
\hline
\end{tabular}

* Authors' translation from Italian.

mension give an idea of the problems experienced by construction workers in terms of complying with the safety rules at work. This can be difficult, because they have to work quickly, and also because adopting all the safety procedures requires a lot of time, the workers are too much fatigued to accomplish, and they think they could even lose their job if they spent too much time on safety matters. This dimension may appear significantly different when comparing the responses of construction workers with different ethnicities, as it can be related to more precarious working conditions of construction workers from specific geographic areas, who can be less likely to have a permanent position as employees of a construction company.

The second dimension recognized was named "danger perception." It is a measure of the perceived grade of consciousness that a job is intrinsically dangerous. The items included in this dimension reflect the experience of workers in the construction sector, and the reported experi- ences from their colleagues; they may know that working in the construction sector is intrinsically dangerous, even more dangerous than working in other sectors. The condition of being a foreign worker may affect this dimension as it is widely reported that foreign workers have higher rates of occupational injuries than native workers, both in Italy and in other countries [1,15-17,22,23].

The third dimension identified was named "safety climate." Safety climate is highly relevant for the safety of workers in an organization, as it represents the way by with safety rules are interiorized in organizations and so perceived by workers through relations with their colleagues and supervisors. Safety climate may predict workers' safety or unsafe personal behaviors, and it can be influenced by actions of other people inside the work team, in particular if they share the same socio-cultural background [21,2428]. The authors included 3 items in this dimension, related to the way workers perceive the necessity of complying 
with safety rules within their work team. The perception of safety climate may change across different ethnic groups of workers, according to their socio-cultural background. The fourth dimension recognized was named an "attitude towards safe actions." This dimension was designed according to the 3 components of attitudes identified in 1960 by Rosenberg and Hovland [29]: cognitive, affective and behavioral. Accordingly, workers may act, or not act, in terms of safety behaviors depending on their beliefs, emotions and personal leanings. The items included here indicate that even quite paradoxical affirmations may be significant in certain groups of workers according to their socio-cultural background and ethnicity. For example, they can misleadingly identify as "brave" the behavior of avoiding the use of protective equipment, or they can look with a sort of fatalistic attitude to the possibility of being seriously injured at work.

To summarize, the 4 dimensions identified within this 12 items questionnaire make it possible to indicate a reference model for the identification of relevant dimensions involved in different risk perceptions by construction workers belonging to various ethnic groups. According to the proposed model, risk perception should be improved with an adequate consideration of ethnicity and cultural background when designing specific preventive interventions to increase occupational health and safety in the Italian construction sector [30]. The most important points to be considered for a better prevention include:

- the necessity of increasing the perception of dangers at work and being conscious that the job could be seriously harmful;

- giving the possibility to workers for easily respecting safety rules, in particular warranting enough time to do the job while adopting all the safety procedures;

- promoting an adequate safety climate within the work organization, involving all co-workers and supervisors;
- sharing the message that safety procedures are not only necessary but also useful and effective in reducing the number of injuries: this will promote a positive attitude towards the adoption of safety measures.

\section{CONCLUSIONS}

This study proposes a new instrument to evaluate risk perception in foreign construction workers in Italy. The tool should be potentially applicable also in other working sectors where a high number of foreign workers is employed, e.g., in agriculture, subject to adapting the items to the characteristics of the working population and specific occupational risks.

The exploratory tool presented by the authors is useful in detecting differences in risk perception, related to the ethnicity and cultural background of workers, according to 4 dimensions identified. The application of the proposed method can be relevant for the identification of more adequate preventive interventions, such as specific training, in the construction sectors.

\section{REFERENCES}

1. Ajzen I. Attitudes, Personality and Behaviour. New York: McGraw-Hill; 2005.

2. Savadori L, Caovilla J, Zaniboni S, Fraccaroli F. The affect heuristic in occupational safety. Med Lav. 2015;106(4):239-49.

3. Slovic P, Finucane ML, Peters EM, MacGregor DG. The affect heuristic. Eur J Oper Res. 2007;177:1333-52, https://doi. org/10.1016/j.ejor.2005.04.006.

4. Kunreuther H, Miller L. An Interactive Modelling System for Disaster Policy Analysis. Washington: American Society for Public Administration; 1985.

5. Bawa VS, Brown SJ, Klein RW. Estimation Risk and Optimal Portfolio. Amsterdam: North-Holland Publications Company; 1979.

6. Lalonde M. A new perspective on the health of Canadians. A working document. Ottawa: Government of Canada; 1974. 
7. Modenese A, Korpinen L, Gobba F. Solar Radiation Exposure and Outdoor Work: An Underestimated Occupational Risk. Int J Environ Res Public Health. 2018;15(10):E2063, https://doi.org/10.3390/ijerph15102063.

8. Pinto A, Nunes IL, Ribeiro RA. Occupational risk assessment in construction industry - Overview and reflection. Safety Sci. 2011;49(5):616-24, https://doi.org/10.1016/j.ssci. 2011.01.003.

9. Maderthaner R, Guttmann G, Swaton E, Otway HJ. Effect of distance upon risk perception. J Appl Psychol. 1978; 63(3):380-2, http://doi.org/10.1037/0021-9010.63.3.380.

10. Weinstein NH. Taking care. Understanding and encouraging self-protective behavior. Cambridge: Cambridge University Press; 1988.

11. Guldenmund F, Cleal B, Mearns K. An exploratory study of migrant workers and safety in three European countries. Safety Sci. 2013;52:92-9, https://doi.org/10.1016/j.ssci. 2012.05.004.

12. Guldenmund F, Chen M, Cleal B, Mearns K. The Relationship Between Accidents of Foreign Workers and Their Cultural Background; An Exploratory Study. Delft: Delft University of Technology; 2010.

13. De Pasquale F, Favero G, Ferrari D, Gobba F, Bravo G, editors. [Percezione e rappresentazione del rischio in edilizia] [Internet]. Modena: Regione Emilia-Romagna, AUSL Modena; 2012 [cited 2019 May 13]. Available from: http://www.osservatorioprevenzione.eu/Biblioteca-Archivio/Materiali/2012\%20 09\%2011\%20Percezione\%20Rischio\%20vol1.pdf. Italian.

14. Giraudo M, Bena A, Costa G. Migrant workers in Italy: an analysis of injury risk taking into account occupational characteristics and job tenure. BMC Public Health. 2017;17(1):351, https://doi.org/10.1186/s12889-017-4240-9.

15. Gobba F, Dall'Olio E, Modenese A, De Maria M, Campi L, Cavallini GM. Work-Related Eye Injuries: A Relevant Health Problem. Main Epidemiological Data from a Highly-Industrialized Area of Northern Italy. Int J Environ Res Public Health. 2017;14(6):E604, https://doi.org/10.3390/ ijerph14060604.
16. Riccò M. Air temperature exposure and agricultural occupational injuries in the Autonomous Province of Trento (20002013, North-Eastern Italy). Int J Occup Med Environ Health. 2018;31(3):317-31, https://doi.org/10.13075/ijomeh.1896.01114.

17. Riccò M, Garbarino S, Bragazzi NL. Migrant Workers from the Eastern-Mediterranean Region and Occupational Injuries: A Retrospective Database-Based Analysis from NorthEastern Italy. Int J Environ Res Public Health. 2019;16(4): E673, https://doi.org/10.3390/ijerph16040673.

18. Micheli M, Zanaletti G, Giorgi I, Argentero P, Candura SM. [Accident risk perception in high-voltage electrical maintenance workers]. G Ital Med Lav Ergon. 2006:28(1 Suppl. 1): 7-14. Italian.

19. Ricci F, Chiesi A, Bisio C, Panari C, Pelosi A. Effectiveness of occupational health and safety training: A systematic review with meta-analysis. J Workplace Learn. 2016;28(6):355-77, https://doi.org/10.1108/JWL-11-2015-0087.

20. Peterson RA. A Meta-Analysis of Variance Accounted for and Factor Loadings in Exploratory Factor Analysis. Marketing Letters. 2000;11(3):261-75, https://doi.org/10.1023/A: 1008191211004.

21. Ajzen I. From Intentions to Actions: A Theory of Planned Behavior. In: Kuhl J, Beckmann J, editors. Action Control. Berlin: Springer Series in Social Psychology; 1985. p. 11-39.

22. Ahonen EQ, Benavides FG. Risk of fatal and non-fatal occupational injury in foreign workers in Spain. J Epidemiol Community Health. 2006;60(5):424-6, https://doi.org/ 10.1136/jech.2005.044099.

23. Salminen S. Are Immigrants at Increased Risk of Occupational Injury? A Literature Review. Ergon Open J. 2011;4:125-30, https://doi.org/10.2174/1875934301104010125.

24. Andersen LP, Karlsen IL, Kines P, Joensson T, Nielsen K. Social identity in the construction industry: implications for safety perception and behavior. Constr Manage Economics. 2015;33(8):640-52, https://doi.org/10.1080/01446193.2015. 1087645.

25. Hale AR, Guldenmund FW, van Loenhout PLCH, Oh JIH. Evaluating safety management and culture interventions 
to improve safety: Effective intervention strategies. Safety Sci. 2010;48(8):1026-35, https://doi.org/10.1016/j.ssci.2009. 05.006 .

26. Reiman A, Pedersen LM, Väyrynen S, Sormunen E, Airaksinen O, Haapasalo H, et al. Safety Training Parks - Cooperative Contribution to Safety and Health Trainings. Int J Constr Edu Res. 2019;15(1):19-41, https://doi.org/10.1080/1557 8771.2017.1325793.

27. Zohar D. Safety climate in industrial organizations: theoretical and applied implications. J Appl Psychol. 1980;65(1):96102, https://doi.org/10.1037/0021-9010.65.1.96.

28. Zohar D. Thirty years of safety climate research: reflections and future directions. Accid Anal Prev. 2010;42(5):1517-22, https://doi.org/10.1016/j.aap.2009.12.019.
29. Rosenberg MJ, Hovland CI. Attitude Organization and Change: An Analysis of Consistency among Attitude Components. New Haven: Yale University Press; 1960.

30. Ricci F, Pelosi A, Panari C, Chiesi A. Safety Training 4.0: Active, Collaborative, Human-Focused Practices, to Improve Health at Work. In: Peruzzini M, Pellicciari M, Bil C, Stjepandić J, Wognum N, editors. Transdisciplinary Engineering Methods for Social Innovation of Industry 4.0. Amsterdam: IOS Press; 2018. p. 310-9.

This work is available in Open Access model and licensed under a Creative Commons Attribution-NonCommercial 3.0 Poland License - http://creativecommons.org/ licenses/by-nc/3.0/pl/deed.en. 